\title{
Citizen Science for Observing and Understanding the Earth
}

\author{
Mordechai (Muki) Haklay, Suvodeep Mazumdar, and Jessica Wardlaw
}

\begin{abstract}
Citizen Science, or the participation of non-professional scientists in a scientific project, has a long history-in many ways, the modern scientific revolution is thanks to the effort of citizen scientists. Like science itself, citizen science is influenced by technological and societal advances, such as the rapid increase in levels of education during the latter part of the twentieth century, or the very recent growth of the bidirectional social web (Web 2.0), cloud services and smartphones. These transitions have ushered in, over the past decade, a rapid growth in the involvement of many millions of people in data collection and analysis of information as part of scientific projects. This chapter provides an overview of the field of citizen science and its contribution to the observation of the Earth, often not through remote sensing but a much closer relationship with the local environment. The chapter suggests that, together with remote Earth Observations, citizen science can play a critical role in understanding and addressing local and global challenges.
\end{abstract}

\section{Introduction}

The term Earth Observation (EO) emerged in the late 1950s and 1960s to describe the use of space technology to observe and monitor natural and human-made phenomena across the globe. EO received an important boost in the concerted effort of scientists from many countries during the International Geophysical Year (IGY 1957-1958). In the period before the IGY, it was suggested that Earth-orbiting satellites will transform our understanding of the physical environment (e.g. Kaplan

The original version of this chapter was revised. An erratum to this chapter can be found at https://doi.org/10.1007/978-3-319-65633-5_19

M. (Muki) Haklay ( $₫)$

Extreme Citizen Science Group, UCL, London, UK

e-mail: m.haklay@ucl.ac.uk

\section{S. Mazumdar}

Department of Computing, Faculty of Arts, Computing, Engineering and Sciences, Sheffield Hallam University, Sheffield, UK

e-mail: s.mazumdar@shu.ac.uk

J. Wardlaw

Faculty of Engineering, University of Nottingham, University Park, Nottingham, NG7 2RD

e-mail: jessica.wardlaw@nottingham.ac.uk 
1956, p. 4). Indeed, the IGY saw the launch of Sputnik, the first human-made satellite, and the opening of the "Space Age". A decade later, in 1966, in light of rapid advances in space technology, an analysis of the potential of EO predicted a wide range of applications: from mapping parts of the world that were not yet mapped, to monitoring wildlife or forest fire, managing air pollution and many other benefits in the fields of geography, agriculture, water resources, oceanography, geology and archaeology (Willow Run Laboratories 1966). EO is the epitome of 'Big Science' (Ravetz 2006) - large-scale scientific endeavours, requiring complex and extremely expensive instruments, and meticulous planning and cooperation across the globe. Moreover, the data that arise from these efforts require specialist skills and tools (e.g. computers in the 1960s), which puts it beyond the abilities and financial reach of non-professional scientists. EO, in short, emerged when the role of the amateur scientist was diminishing, and the scope for members of the general public to participate meaningfully in cutting-edge scientific research became very limited.

And yet, the participation of non-professional scientists-people who have interest in scientific research but operate outside scientific institutions-is an integral part of the process of observing and understanding the Earth. Even in the early days of EO and the IGY in 1957, thousands of amateur scientists-nowadays called citizen scientists-participated in tracking these very early satellites (McCray 2006). Under the leadership of Fred Whipple, the then head of the Smithsonian Astrophysical Observatory, amateurs were engaged in identifying satellite locations in close collaboration with professional scientists. The Moonwatch project, which continued to run until 1975, involved participants in optical observation of satellites as they orbit the Earth. The programme faced obstacles and scepticism from other scientists and administrators of the IGY, as they did not trust the volunteers to provide sufficiently high quality information and observations. Eventually, though, it was a group of Moonwatch volunteers who first observed the Sputnik (McCray 2006). In many ways, the story of Moonwatch is mirrored in current citizen science projects that are the focus of this chapter.

The 1966 analysis (Willow Run Laboratories 1966) is striking for its emphasis on aspects of EO that are now taken for granted: a set of instruments, with predictable characteristics, taking many readings over large areas of the Earth in a consistent way, and enabling scientific analysis at scales that could not exist before. The ability to capture information over large areas automatically is presented in contrast to the difficulties of large-scale observations on the ground: for example, through a network of meteorological observations by volunteers and professional observers that can potentially be replaced by satellite measurements. Eventually, meteorology demonstrates, though, that the satellite has not replaced the observers on the ground completely. Although the area of meteorology relies on a vast array of automated sensing systems, satellite observations and a large and well-funded professional observation network, there is still a role for volunteers who can report information from their homes. More generally, instead of an assumption that a set of automated instruments will eventually replace the contribution of observers on the ground and that the non-professional scientist will eventually be consigned to history, a more 
nuanced picture has emerged, in which citizen scientists, professional scientists and EO experts are working collaboratively to address local and global challenges.

Societal and technological changes underlie this transition in the area of EO, and the next section will explore the trends that have led to the current incarnation of citizen science. Following this, we provide an overview of the main areas that are covered by citizen science, using a typology that shows how both old and new approaches to citizen science shaped the current landscape. The typology does not cover the full range of citizen science activities, but rather highlights sample activities along three axes: domains of scientific activities, reliance on digital technologies and level of engagement of participants in shaping projects. We also use the typology to introduce a range of projects that demonstrate each type of citizen science activity area within the area of Earth Observations. Following these examples, we suggest some of the critical technical and societal aspects of citizen science in the context of EO.

\section{Societal and Technological Trends}

While public participation in scientific efforts has the long history that was noted above, the final decade of the twentieth century marked the beginning of a new form, which received the name citizen science. The first recorded use of the term is in 1989 and describes how 225 volunteers across the USA collected rain samples to assist the Audubon Society, a nature conservation organisation, in an acid-rain awarenessraising campaign (Kerson 1989). The volunteers collected samples, checked for acidity and reported back to the organisation, therefore creating coverage across the continent and demonstrating the extent of the acid-rain phenomenon.

The term continued to gain recognition slowly throughout the 1990 s (e.g. Bonney 1996). The past decade has seen a rapid increase in the number of citizen science projects and their scale. As a result, citizen science is now the accepted term for a range of practices. The term was first noted in Wikipedia in 2005 and recognised by the Oxford English Dictionary in 2014 as "scientific work undertaken by members of the general public, often in collaboration with or under the direction of professional scientists and scientific institutions" (OED 2014).

In addition to the term citizen science, this form of public involvement in scientific research has also been termed Public Participation in Scientific Research (PPSR), participatory science, civic science and amateur science, as well as crowdsourced science. In specific areas of scientific research, citizen scientists are known by domain-specific terms such as birdwatchers, amateur astronomers, volunteer weather observers or amateur archaeologists. This variety points to the longevity of the practice and the current convergence under an umbrella term due to the growing importance of these practices.

As was noted in the introduction, there are many parallels between the early days of citizen science participation in EO and its current incarnation. Yet, when 
examining the current scale and depth of engagement, current citizen science has clearly moved beyond previous forms of public involvement in scientific research.

Several societal and technological trends help to explain the emergence of citizen science today. These include the rapid growth in (especially higher) education during the second part of the twentieth century, increased leisure time (especially in middle and high income countries), and growth in educated and able retirees. On the technical side, the growth of the Web and mobile communication, and the ubiquitous connectivity that they offer, is highly significant. In particular, the emergence of Web 2.0 and the evolution of peer-production systems in the past 10 years, as well as the development and proliferation of cheap sensors that can collect data from the environment, played an important role. We now turn to look briefly at each of these.

The second half of the twentieth century has seen a major transformation in education across the world, with countries such as the UK moving from $1.6 \%$ of the population with a tertiary level of education in 1950, to $21.7 \%$ in 2010 (Barro and Lee 2012). This translates into a rise from $<1$ in 50 to over 1 in 5 in the span of 60 years. More generally, across advanced economies, the rate rose from $2.8 \%$ in 1950 to $17.9 \%$ in 2010 . Importantly, this transition happened while the size of the population itself increased almost twofold, and significant improvements occurred at all levels of education, as both culture and education across the developed world became more oriented towards scientific thinking (Flynn 2007). This education shift has provided many millions of people across the world with the cognitive ability to understand abstract concepts, logic and hypothetical ideas. Education levels continue to increase across the world with an estimated 240 million people studying for tertiary education in 2013, of which about 2.5 million are studying at doctoral level (UIS 2015). Of course, not every person in tertiary education studies Science, Technology, Engineering and Mathematics (STEM) topics and yet the number of people who can potentially participate in citizen science without intensive training in the principles of the scientific method, or in the need for accurate measurements and the necessity to follow data collection protocols rigorously, is very large and will continue to increase.

In conjunction with the rise in levels of scientific education, the time dedicated to work in advanced economies decreased during the late twentieth century, down to about $40 \mathrm{~h}$ across OECD countries. The introduction of a 2-day weekend across advanced economies during the middle part of the century freed up time for leisure, hobbies, volunteering activities and family time.

The final societal aspect of note in the context of this discussion is increased life expectancy, which, combined with slow changes in retirement age, has led to a growth in educated and healthy people in their 60s and 70s who are active in their communities. For some, citizen science provides a way of re-engaging with topics of science that they studied earlier in their life, but have not engaged with during their working career.

On the technical side, the main factors are more familiar and have been covered extensively in the media and academic literature (e.g. Cuff et al. 2008; Haklay et al. 2008; Haklay 2013). Especially within the context of EO, we can identify 
several important trends. First is the growth of the Web and the ability to access scientific information through platforms from Wikipedia or lectures recorded on YouTube, to scientific papers that are shared through repositories and Open Access journals. Moreover, the Web is not only a conduit to consume scientific knowledge but also a suitable medium for creating new ways of engaging very large groups of people (which are referred to as the Crowd) to perform tasks and shared activities. Frequently described as user-generated content, the Web ushered in a new form of interaction between people with limited technical capacity and web-based systems, in which they could share news and information about their locality with a potentially global audience. From the point of view of EO, the ability of participants to generate geographic information and share it is especially important, and this was recognised by Mike Goodchild in 2007 as Volunteered Geographic Information or VGI (Goodchild 2007). Another aspect of this new mode of interaction is the ability to engage thousands and even millions of participants in performing small tasks that, in aggregate, yield significant results, as well as involving a very large group of participants in solving problems (this is known as crowdsourcing).

The ability to generate VGI is also linked to the removal of the selective availability of the Global Positioning System (GPS) signal in May 2000, and the subsequent proliferation of GPS receivers and location-based technologies (Haklay et al. 2008). The provision of an easy-to-use and automated location tracking and recording mechanism that can be easily communicated with latitude and longitude coordinates attached as metadata to different items of information (geotagging) is highly significant to citizens' participation in EO. With the advance of VGI, geotagged images from people's smartphones are available in quantities and at temporal and spatial scales that were never seen before and, more importantly, shared in a machine-readable way (e.g. Antoniou et al. 2010).

However, while GPS receivers are vital ingredients of EO, many other sensors also reduced in size and cost, due to the proliferation of smartphones with computing and sensing abilities in the past decade. It is now common to have multiple sensors in a smartphone, including a barometer, camera, microphone, accelerometer, electronic compass and more, which are integrated into the device to enable its functioning (e.g. the ability to acquire location rapidly in the case of the barometer) but can be reused by a range of applications to perform scientific measurements.

Next, we should also note the growth in internet bandwidth both at home and through mobile telecommunication networks. At home, the ability to send and receive videos and large image files, as well as rapid and responsive interaction with websites, is critical to many citizen science projects. Moreover, the possibility to stay connected while on the move increases the volunteers' ability to record and share observations quickly and easily: sometimes as small tasks that last a few seconds (micro-tasks) or even by carrying the device itself passively.

Finally, and most recently, there has been a growth in Do-It-Yourself (DIY) electronics with the introduction of easy-to-programme control boards or miniaturised computers (such as Arduino or Raspberry Pi), 3D printers allowing rapid prototyping and small-scale manufacturing, and hubs such as Makers clubs and Hackspaces where people meet and work together to develop new devices and 
projects. The falling cost of sensors and components that was mentioned above, and the practice of sharing of information over collaborative websites, opened up the ability of mostly technically savvy people to carry out their own DIY science efforts.

The trends have fundamentally altered citizen science. Most of the public in the early twentieth century could not be relied upon to identify and report the scientific names of species (though some expert amateur naturalist has done so) and were not equipped with scientific understanding; nor were they carrying around powerful scientific instruments in their pockets. In contrast, today, hundreds of millions of people have such abilities, and therefore the potential for participation is much higher. Yet, it is important to note how the multiple underlying trends are also defining the demographics of those who participate in citizen science. Participants in citizen science activities are typically well educated, working in a job that provides enough income and working conditions for ample leisure, and have access to the Internet as well as own a smartphone. Not surprisingly, because of the imbalances in care responsibilities, science education and income, men are overrepresented in citizen science. For example, a study found that $87 \%$ of the participants in a volunteer computing project (see the next section) were men (Krebs 2010), while a similar bias was identified in ecological observations of birds (Cooper and Smith 2010). Internationally, citizen science is concentrated in advanced economies, especially the USA and northern Europe. The need to access the Internet still presents an obstacle, with level of access ranging from $87 \%$ in the UK, to $81 \%$ in the USA, and only 65\% in European countries such as Poland or Portugal (ITU 2013). At the more local level, even for those who have access to a smartphone, many of the software applications (apps) that support citizen science assume continuous and seamless Web connectivity, even though $3 \mathrm{G}$ and $4 \mathrm{G}$ coverage is partial in highly urbanised environments such as London or New York City, let alone in remote nature reserves. Language can also present a barrier. As the background material and the apps are being developed by scientists, the amount of disciplinespecific jargon and the level of understanding that is needed to get involved in a project can exclude many people. Finally, since English is the main language of scientific papers and of science more generally, many of the tools and technologies that support citizen science activities rely on knowledge of English, and are not available in local languages, especially in areas of high cultural heterogeneity such as Europe.

The result is somewhat ironic. Much of the rhetoric of citizen science is about its potential for inclusion of new groups in society, raising awareness and interest in the scientific enterprise, and providing new routes for education and skills. The current demographics demonstrate that, without purposeful effort, this will not happen. Sometimes, there are simple routes to overcoming challenge (e.g. to provide paper forms in areas of low connectivity) but, more generally, special attention should be paid to those that are, mostly unintentionally, excluded from citizen science activities. 


\section{Citizen Science Today: Main Areas of Activity}

The aforementioned trends provide an explanation of the current integration of citizen science within EO activities. In this section, we will look at a general typology of major types of activities in citizen science, which are identified by their domain, technical needs and the level of engagement of participants in the projects.

Figure 1 presents the topics that the following sections will cover. Under the banner of citizen science we can see three types of activities, each highlighting a different facet of the field. First, long-running citizen science is defined by activities that involve the public in areas where the practice of working in collaboration with non-professional scientists is well established. There are many areas of science in which volunteers continue to play a role in research and, from the perspective of EO, ecological and biological observations, weather observations and participation in archaeology provide good examples of the potential of citizen science. Other areas, such as astronomy, have also demonstrated sustained engagement with citizen science. The next type of citizen science projects highlights the way technology influences citizen science, and includes projects that rely on the Internet and the Web. These citizen cyberscience projects use the ability of computers as both computing and communication devices to engage citizen scientists. In fact, projects that fall under this category would not have existed without the proliferation of computers and the Internet. Here we find volunteer computing, which utilises the unused computing resources of participants' computers; volunteer thinking, which asks the participants to contribute through their cognitive abilities; and passive sensing, which relies on the sensors that are integrated into mobile computing devices to carry out automatic sensing tasks. The final group of citizen science projects that will be discussed here emphasises the depth of engagement of participants, and we will term these as community science-projects that are carried out as part of local, everyday settings, to address local concerns and needs. Here we look at three types of activities: participatory sensing, a joint activity between researchers and members of the public with varied levels of participation in setting what will be

\section{Citizen Science}

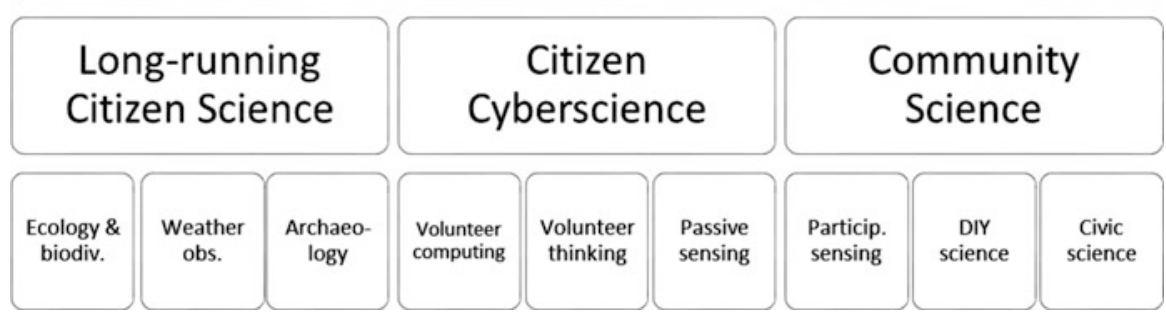

Fig. 1 Mapping current citizen science activities by domains, technology and engagement 
detected, where and how it will be analysed; DIY science, in which participants create the scientific instrument themselves, and repurpose a range of materials and tools to build laboratories and carry out their enquiries; and, finally, civic science, which covers scientific activities that aim to build relationships between the public, experts and policy makers and enable them all to participate in scientific knowledge production (Bäckstrand 2003). This type of scientific practice can also be recognised as bottom-up science (McQuillan 2014).

To understand how each of these families of citizen science operates and their relevance to EO, the following sections will look at each, in turn.

\section{Citizen Science Across Domains: Long-Running Citizen Science}

At first sight, there are many areas of scientific activities that continued to engage with non-professional scientists throughout the era of Big Science: birdwatching in biological and ecological observations (Kobori et al. 2016, Bonney et al. 2009), recording of meteorological conditions (WMO 2001), and volunteers in archaeological digs (Clarke 1978) are all examples of sustained engagement of citizen scientists. However, the aforementioned trends have changed the interaction with volunteers and the way in which they carry out their work and, especially, share information.

For example, new technologies are making a step change in the relevance of volunteered ecological and biodiversity observations for wider EO systems. Historically, amateur naturalists (as they were known) recorded information in their notebooks, frequently using idiosyncratic records management systems, and the sharing of the information with others was partial. As August et al. (2015) discuss, the use of digital technologies not only supports the immediate sharing of information, but also contributes in a structured way: for example through predefined forms on websites and increased use of apps on smartphones, which provide further information such as GPS coordinates, geolocated images or audio recordings (Jepson and Ladle 2015, Powney and Isaac 2015). In some of these systems and apps, information can appear in global databases (e.g. the Global Biodiversity Information Facility-GBIF) instantaneously. Therefore, through the link between more educated volunteers and ICT-enabled streamlined sharing, current citizen science contributes to the creation of EO systems in the area of biodiversity.

As noted, the participation of volunteers in weather and meteorological observations is also well documented. The network of meteorological observations is one of the longest-standing examples of citizen science, with many thousands of volunteers reporting local meteorological conditions to national organisations, which improves the quality of modelling and understanding weather and climate (WMO 2001). As such, this area demonstrates a union between citizen science and established professional science that is both persistent and evolving over time through the development of instruments and the abilities of participants. For 
example, the commercial provider of meteorological forecasts, The Weather Company, is managing a large-scale crowdsourcing aggregation of weather observations through the Weather Underground network. A network of over 180,000 participants link observations from their personal weather stations to improve The Weather Company's predictions, and benefit by receiving personalised forecasts. Another example of the scale and scope of citizen science in this area is provided by the UK Met Office Weather Observation Website (wow.metoffice.gov.uk), which received 38 million observations in its first year of operation in 2011 (POST 2014), and provides a source of additional information for the Met Office that is especially useful during extreme weather events. Here, too, technological advances streamlined and standardised information sharing, while the increased awareness and skills in the general public contributed to greater participation in reporting.

Archaeology is another field with a tradition of voluntary participation with historical links to EO. Looking back at the 1966 report (Willow Run Laboratories 1966), satellites were seen as an extension of aerial photography, which was already in use at the time in archaeology. However, while satellite instruments were expected to assist in identifying large features, such as buried cities, "... the requirements for the use of such sensors in the detection of small features remain very near and possibly beyond the capabilities of orbital sensor equipment as presently envisioned" (p. 153). Today, there is a flourishing sub-discipline of Space Archaeology, which uses the abilities of EO to advance the field. Citizen science, in the form of crowdsourcing, now addresses the exact problem that, 50 years ago, was considered beyond the possible. In 2010, Albert Yu-Min Lin and colleagues devised a system based on high resolution satellite imagery to engage over 10,000 volunteers in the task of assessing potential locations for the unknown burial site of Genghis Khan (Lin et al. 2014). The system asked volunteers to evaluate an area visually and mark locations that they considered as potentially interesting. The ability to engage a huge number of volunteers enabled the examination of a very large area $\left(6000 \mathrm{~km}^{2}\right)$, yielding 55 candidate sites for further archaeological studies on the ground. The application that was developed for this task eventually evolved into the Tomnod system, now used by Digital Globe for humanitarian and other crowdsourcing efforts. Here, the ability of people to collaborate online is significant, and vividly demonstrates the importance of broadband and the bidirectional web in opening up new avenues for collaboration between professional and non-professional researchers.

\section{The Impact of Technology: Citizen Cyberscience}

As the overview noted, the emergence of the Internet and the Web as a global infrastructure has enabled a new incarnation of citizen science, which has been termed citizen cyberscience by Francois Grey (2009) and could not possibly have existed before. Characteristically it relies on the proliferation of billions of connected personal computing devices-desktop computers, smartphones and 
games consoles-and utilises the computational and sensing power of these devices to double as scientific instruments. If the previous section considered how citizen science is integrated into different scientific disciplines, here we look at how advances in personal computing transformed the potential of citizen science in contributing to EO. In particular, we will focus on three subcategories: volunteered computing, volunteered thinking and passive sensing.

Volunteered computing was first launched in 1999, with the SETI@ home project (Anderson et al. 2002), which exploits the unused processing capacity in personal computers and uses the Internet to send and receive work packages that are analysed automatically and sent back to the main server. The system on which SETI@ home is based, the Berkeley Open Infrastructure for Network Computing (BOINC), is now used for over 100 projects. While volunteer computing is popular in the area of biological and medical research, it is not well utilised in the area of EO. An example of the potential of volunteer computing is provided by the ClimatePrediction.net project, which was established by climate researchers at the University of Oxford in 2002 and, with exposure from mass media, reached 60,000 volunteers. In the early months of 2014, when the project team wanted to suggest the degree to which recent floods could be attributed to climate change, they were able to run over 33,000 different models and demonstrate that it is highly likely that the floods were more severe due to climate change (Climateprediction.net 2014).

While volunteered computing asks very little from the participants, apart from installing software on their computers, volunteered thinking engages volunteers at a more active and cognitive level (Grey 2009). In these projects, participants use a website in which information or an image is presented to them. They are provided with a little training in the task of classifying the information, after which they are exposed to information that has not been analysed and are asked to carry out classification work. Galaxy Zoo (Lintott et al. 2008) is one of the most well-known and developed examples of volunteer thinking. Over 100,000 volunteers classified images of galaxies for this project, and it spawned a range of applications that are included in the wider Zooniverse set of projects (see http://www.zooniverse. org/). We have already encountered one example of volunteer thinking work in the previous section, with the effort to locate Genghis Khan's tomb.

Another highly relevant example of the involvement of volunteer thinking in EO is provided through the OpenStreetMap project (Haklay and Weber 2008). This distributed project has now engaged millions of people in mapping their area through a combination of tracing satellite imagery and on the ground survey, as demonstrated by the "Missing Maps" project (Feinmann 2014) in which areas that were not mapped before are being added to OpenStreetMap to support humanitarian efforts.

The final example of citizen cyberscience is provided by passive sensing, in which participants either connect sensors to their computers or smartphones, or use the built-in sensors that are available in devices, to support EO efforts. Unlike participatory sensing, which we will encounter in the next section, passive sensing is mostly based on automatic data capture and sharing, without the conscious intervention of the volunteer. We have seen one example of such passive sensing 
in the Weather Underground network above. The personal weather stations that are linked to the network operate automatically, mostly without intervention from their owner, and, once they are set to deliver the information to The Weather Company's server, they will continue to do so. However, further potential for EO integration is provided via mobile devices. For example, the Quake Catcher Network (QCN) is utilising the movement sensors that are integrated into some laptop computers, to enhance observations from existing seismic observation stations (Cochran et al. 2009). QCN is improving the quality of seismic information that is emerging from events. Interestingly, QCN is utilising the BOINC framework but extends it by linking to sensors.

\section{Depth of Participation: Community Science}

Community science is a term used here to describe citizen science projects with a significant element of bottom-up control over the project; at its extreme, activities are initiated and driven by a group of participants who identify a problem that is a concern for them and address it using scientific methods and tools. The problem definition, data collection and analysis might be carried out by community members or in collaboration with scientists in established laboratories whose role is to support and carry out work on behalf of the community members. This is in contrast to the types of citizen science discussed above, where the scientific research question, data collection methodology and the analysis are all done by professional scientists and the role of participants is somewhat restricted.

In the area of community science, three examples demonstrate the role of participants and professional scientists, and their potential of integration with EO.

First, participatory sensing is defined as sensing activity in which a group of participants contribute together to a body of information. Importantly, while the term is now used liberally to describe a wide range of crowdsourced sensing activities with varying levels of active engagement with the citizen scientists who will carry out the sensing, in the original definition (Burke et al. 2006; Goldman et al. 2009), "Participatory Sensing emphasizes the involvement of citizens and community groups in the process of sensing and documenting where they live, work, and play ..." (p. 4). Unlike passive sensing, the participants are expected to take a more significant role in shaping the sensing project. In its simple form, participatory sensing requires lower cognitive effort from participants and relies on users to provide sensory information in a structured manner via their mobile devices and cloud services (Estrin 2010). The participants select when and where to carry out data collection, but the application and the data infrastructure are set. The examples that were mentioned above of apps for ecological and biodiversity recording operate under this scheme-many of the apps that are provided to volunteers (see Jepson and Ladle 2015, Powney and Isaac 2015) expect participants to take an image of the species that they have identified using their smartphones and share them by adding them to national or global databases. Another interesting example is Ikarus 
(http://thermal.kk7.ch/), where paraglider flight log data is collected and processed to generate thermal maps. With a large number of paragliders and flight paths, Ikarus is one of the largest participatory sensing initiatives (Von Kaenel et al. 2011).

In contrast, the practices of DIY science mean that the participants develop instruments, methodologies for data collection and analysis (Nascimento et al. 2014). This requires very deep engagement from the participants, as well as technical and scientific knowledge to carry out the scientific study in question. In the area of EO, we can see an emerging interest in the development of devices and software that can facilitate balloon and kite mapping, for example by the Public Laboratory for Open Technology and Science (Public Lab for short). By using simple adapted technology, digital cameras are strapped to balloons or kites and used to observe and analyse local conditions. Simple adaptation can convert a camera to near-infrared, and thus provide information at other wavelengths than visible light (Breen et al. 2015). Moreover, if the group who collected the data wishes, this very detailed local mosaic can be shared through Google Earth.

The final type of community science is civic science, which is explicitly linked to community goals and questions the state of things. While some DIY science is done from such a perspective (e.g. Breen et al. 2015), civic science can also include work with indigenous communities in the use of smartphones to record community resources and other local features, even when the participants are non-literate (Stevens et al. 2014). While the approach is highly sensitive to local cultural practices and involves a lengthy discussion about information sharing to ensure consent, it can be integrated into larger EO systems, providing the unique perspective of local and traditional ecological knowledge.

\section{Citizen Science and Earth Observation: Technical, Societal, Ethical and Policy Aspects}

Based on this overview of citizen science and understanding of the areas that it covers, the main methods that are used in it and their linkage to EO systems, we now turn to common issues that are discussed in respect of citizen science and EO. Here we focus on technical, societal and ethical aspects, and the policy issues that can facilitate or hinder this integration.

\section{Technical Aspects}

An ever-increasing number of citizen science or crowdsourcing initiatives continue to engage user communities in scientific endeavours, incorporating a variety of mechanisms for collecting, presenting and analysing crowdsourced informationsome of them with hundreds of thousands of participants (e.g. Lintott et al. 2008; 
Fishwick 2014). While the engagement of large numbers of volunteers is always encouraging, increased volumes of data do not necessarily imply the presence of more useful information (Mackechnie et al. 2011). Data collected by citizens may lack metadata regarding their quality, which can often lead to being discredited by many scientists (Alabri and Hunter 2010). Although many studies (e.g. Newman et al. 2003; Foster-Smith and Evans 2003; Fore et al. 2001) have found volunteers can collect comparable data to professional researchers (with limitations), there is a need for a methodological approach towards addressing quality concerns in citizen science data; even a traditional consensus-based approach to volunteered data is non-trivial to apply (Salk et al. 2017). It is only expected that citizen science and crowdsourced data, owing to its increasing relevance and contribution to scientific outcomes, should also adhere to similar strict and rigorous validation processes in the specific fields, for example in meteorology or biodiversity observations, as we have seen above. This calls for a need to have a good understanding of the validation mechanisms that can be potentially applied to citizen science initiatives to mitigate against the potential economic (Foody 2015) and policy implications that we will see later.

Haklay (2016) identified six mechanisms that citizen science initiatives typically employ for quality assurance: some rely on the principle of abundance where validity of information is based on agreement by other observers (crowdsourcing) or other volunteers more experienced than the original observer (social). Validation mechanisms can also involve either the presence of geographical or domain expertise. Several initiatives rely on measuring instruments to provide their quality, precision and accuracy (instrumental observation), which can, in turn, indicate the validity of observations. Finally, the more formal process oriented relies on trained participants for collecting and storing observations in a highly structured manner, using standard equipment. One or a combination of validation mechanisms is typically employed in citizen science initiatives. For example, the COBWEB (Higgins et al. 2016) and WeSenseIt projects employ multiple levels of validation such as position accuracy (instrumental observation), linked data and various forms of automated data validation (domain). The recently concluded Crowd4Sat project's (see http://www.crowd4sat.eu/) demonstration projects individually employ a few validation mechanisms such as crowdsourcing, geographical and instrumental observation.

Citizen science can also be used to improve EO data. For example, EO data is prone to errors and inconsistencies arising from the very nature of its sensing. For example, an intrinsic problem with measuring water or snow coverage in mountainous regions with Synthetic Aperture Radar (SAR) imaging is the slantrange distortion effect. This leads to inaccurate assessments of snow and water cover. Providing mechanisms for special interest communities such as hikers, wildlife enthusiasts and photography groups who frequent such areas can provide critical fine-grained spatial data to help rectify such issues.

Another issue is that, while satellites can provide critical information during emergency events, they typically have revisit times that are too low to address urgent issues. Flooding, for instance, is an emergency scenario where situations 
can drastically deteriorate in a very short time. In such scenarios, passive and opportunistic participatory sensing information can improve the temporal resolution of information critical to emergency responders (Endsley 1995) and thus improve data availability and quality.

Another critical aspect of the integration of citizen science data and EO is information integration. In EO, the potential for understanding and predicting natural and human-made processes and phenomena is enormous. However, it involves observing a variety of key variables (e.g. local information, sensor observations, human perception of events and phenomena). Often, the variables of interest are the ones that are most difficult to observe such as flow and velocity, land occupation, etc. However, decision makers can only achieve a holistic view once all the variables are contextualised in the same model and view. Data fusion can provide enriched information from multiple sensor data in a variety of granularities (El Faouzi et al. 2011, Koch 2014) by exploiting spatio-temporal features of data. This is a highly complicated task since different variables represent different characteristics, in different contexts and levels of granularity. One of the findings from the Crowd4Sat project observed that, while satellite observations are on a large scale, human observations are typically on a much smaller scale and, as a result, several discrepancies can arise when trying to use either observation to validate the other. While most citizen science initiatives, in their current state, are independent, effective data fusion and integration techniques promise a more integrated approach, where different citizen science initiatives can inform and provide support for each other as well as share information. The Crowd4Sat project identified this as one of the possible directions where citizen science and crowdsourcing could evolve in the next few years, and potentially change the landscape of citizen science for EO.

\section{Societal and Ethical Aspects}

Citizen science and EO integration is not only a technical issue, but a socio-technical system that requires human and societal perspectives, which need attention if the EO field is to continue extending the activities outlined above in a sustainable manner. Many of these are addressed by the European Citizen Science Association's 10 Principles of Citizen Science (ECSA 2015). These translate into three themes of practical importance to which we now turn: motivations, ethics and privacy.

First, the voluntary participation of citizens is implicit to the practice of citizen science, and this demands attention regarding their motivation to engage and sustain their engagement over time as this could demand financial, societal or other forms of recognition (Geoghegan et al. 2016). As citizen cyberscience activities demonstrate, different activities require different levels of engagement from volunteers. Demands on volunteers' time and resources are associated with a risk of disengagement over the course of the activity on the one hand, and potential exploitation and abuse by those leading the project on the other. 
Citizen science implies elements of engagement in genuine scientific activity and education. In line with standard ethical practices, we can argue that citizen scientists should be treated with respect; informed as to the purpose of their involvement or if this is not possible, and they have been deliberately misled, debriefed; and involved with only non-harmful activities. Another stance is to treat participants as collaborators and not waste their time (Prestopnik and Crowston 2012; ECSA 2015). Participants' informed consent and transparency regarding the storage and use of data are also desirable to mitigate against the increasing privacy concerns discussed next.

In citizen cyberscience and participatory sensing especially, terms such as Human Processing Units, Remote Person Calls and The Human API can all be found in the literature (Reeves 2013; Lease and Alonso 2014), which can be interpreted in a way that dehumanises participants. This may be to the detriment of citizen science projects, as it can harm motivations that we noted above. The fundamental implication of this is clear: citizen science requires consideration of the needs and requirements of public participants.

Within the ethical consideration, we should pay special attention to privacy issues. These are given comprehensive coverage by Bowser et al. (2014) and include a range of data ownership and sharing challenges, not least issues of intellectual property. Advancements in citizens' participation in EO will, however, need a balanced approach towards not only ethics, but privacy and associated legalities. A key concern in fusing crowdsourced data is in understanding the implications of cross-sensor/cross-project/cross-initiative data fusion. For example, in the recently started Big Data project, Seta (see http://setamobility.eu/) has highlighted this as a key concern. The project, aimed at understanding mobility in metropolitan areas, attempts to integrate different forms of motorised and non-motorised crowdsourced data. While anonymisation policies are designed to protect privacy of citizens, integrating data across multiple sensors and facets may pose a significant risk to their identification.

\section{Citizen Science Integration into Policy}

The final aspect of citizen science and EO that we will consider here is the integration of citizen science into policy. This is critical for the wider discussion on open science and this book as, without long-term integration, citizen science will remain in niche activities and, as in the early period of EO, will be treated with suspicion or ignored, and hence will not receive the necessary financial and organisational resources that will enable it to thrive.

One aspect of citizen science that is raising challenges for policy makers is the multiple outcomes that these projects can achieve and the domains to which they contribute. As we have seen, and as many noted (Bonney 1996; Burke et al. 2006; Bonney et al. 2009; Haklay 2015), citizen science can contribute to increasing awareness of participants to science and environmental issues. The training, which 
can lead to an improvement of data quality, can also assist in gaining skills that are not directly linked to the specific project. Citizen science activities such as DIY workshops or ecological surveys can act as science outreach activities, while at the same time teaching participants the value of sharing information. Such multiple goals sometimes mean that there is no single owner or funder for such projects within regular organisational structures, and therefore is a mixed blessing for the field.

However, the scale and reach of citizen science and the visibility of projects over the past decade has raised the attention of policy makers at local, regional, national and international level. Such awareness, and the development of appropriate policies as well as long-term funding mechanisms, is critical to the sustainability of citizen science efforts and ensuring that the information is being used in the long run.

For EO, probably the most significant demonstration of the integration of citizen science and EO is within the Eye on Earth Alliance, which brings together the Abu-Dhabi Global Environmental Data Initiative (AGEDI), the Group on Earth Observations (GEO), the International Union for the Conservation of Nature (IUCN), the United Nations Environment Programme (UNEP) and the World Resources Institute (WRI). The alliance committed at the end of 2015 to promoting the use of citizen science as an integral part of the Sustainable Development Goals (SDG) monitoring activities, in a way that integrates it with EO. There are emerging examples of the use of citizen science in systems such as UNEP Live or the WRI Global Forest Watch. However, these examples are still in an experimental stage, and a transition to fully fledged systems is still in the future. As noted before, and likely due to the urgency associated with it, the one area in which crowdsourcing, citizen science and EO are already being integrated and used is in the humanitarian response to disasters where systems such as OpenStreetMap (Zook et al. 2010) or Tomnod are now routinely used.

\section{Conclusions}

In this chapter, we have introduced the area of citizen science and its relationship with EO. As we have seen, while citizen science has interacted with EO from its very early days, the new incarnation of citizen science provides scale, scope and coverage that transform it into a new component with true global reach. After 50 years of $\mathrm{EO}$, and while there are many challenges ahead, citizen science is evolving into a pivotal provider of information about the planet. Traditional areas of citizen science activities are enhanced by current technological and societal activities and the information that is provided by citizen scientists can now be verified and tested, and therefore be integrated into EO systems faster. New areas, forms of engagement and capabilities also emerged recently, and these also contribute, either through passive or participatory sensing, to the range of activities that can be included in citizen science. 
Yet, as we have seen in the discussion, the long-standing challenges of data quality, data integration, interoperability, management of metadata, engagement, interaction, privacy and ethics are all significant to the process of improving citizen science outcomes and ensuring that it will become a sustainable practice, and that the information that is emerging from it is used in many areas of policy and decision making.

Acknowledgement This chapter is partially based on material that was published in Haklay (2013) and Haklay (2015), which was updated, extended and edited for this chapter. The research was kindly supported by: the UK's Engineering and Physical Sciences Research Council (awards EP/I025278/1, EP/K022377/1); the European Union's Seventh Framework Programme (FP7/20072013) under grant agreements Every Aware (no 265432), Citizen Cyberlab, WeSenseIt (no 308429), and iMars (no 607379); European Union Horizon 2020 projects DITOs, Seta, ECSAnVis; and the European Space Agency's Crowd4Sat. We would also like to thank Berris Charnley for useful comments and suggestions for an earlier version of the manuscript.

\section{References}

Alabri A, Hunter J (2010) Enhancing the quality and trust of citizen science data. In IEEE Sixth International Conference on e-Science. IEEE, Washington, DC, pp 88-81

Anderson DP, Cobb J, Korpela E, Lebofsky M, Werthimer D (2002) SETI@home: an experiment in public-resource computing. Commun ACM 45(11):56-61

Antoniou B, Haklay M, Morley J (2010) Web 2.0 geotagged photos: assessing the spatial dimension of the phenomenon. Geomatica 64(1):99-110

August T, Harvey M, Lightfoot P, Kilbey D, Papadopoulos T, Jepson P (2015) Emerging technologies for biological recording. Biol J Linn Soc 115(3):731-749

Bäckstrand K (2003) Civic science for sustainability: reframing the role of experts, policy-makers and citizens in environmental governance. Glob Environ Polit 3(4):24-41

Barro R, Lee J-W (2012) A new data set of educational attainment in the World, 1950-2010, NBER Working Papers 15902. National Bureau of Economic Research, Cambridge, MA

Bonney R (1996) Citizen Science: a lab tradition. Liv Bird 15(4):7-15

Bonney R, Ballard H, Jordan R, McCallie E, Phillips T, Shirk J, Wilderman CC (2009) Public participation in scientific research: defining the field and assessing its potential for informal science education. A CAISE inquiry group report. Center for Advancement of Informal Science Education (CAISE), Washington, DC

Bowser A, Wiggins A, Shalney L, Preece J, Henderson S (2014) Sharing data while protecting privacy in citizen science. Interactions 21(1):70-73

Breen J, Dosemagen S, Warren J, Lippincott M (2015) Mapping grassroots: geodata and the structure of community-led open environmental science. Int E J Critic Geograph 14(3):849873

Burke JA, Estrin D, Hansen M, Parker A, Ramanathan N, Reddy S, Srivastava MB (2006) Participatory sensing. Center for Embedded Network Sensing, Los Angeles, CA

Clarke DV (1978) Excavation and volunteers: a cautionary tale. World Archaeol 10(1):63-70

ClimatePrediction.net (2014) Weather@home 2014: the causes of the UK winter floods. http:// www.climateprediction.net/weatherathome/weatherhome-2014/. Accessed Aug 2014

Cochran ES, Lawrence JF, Christensen C, Jakka RS (2009) The quake-catcher network: citizen science expanding seismic horizons. Seismol Res Lett 80(1):26-30

Cooper CB, Smith JA (2010) Gender patterns in bird-related recreation in the USA and UK. Ecol Soc 15(4):4. http://www.ecologyandsociety.org/vol15/iss4/art4/. Accessed Aug 2014 
Cuff D, Hansen M, Kang J (2008) Urban sensing: out of the wood. Commun ACM 51(3):24-33

El Faouzi N-E, Leung H, Kurian A (2011) Data fusion in intelligent transportation systems: progress and challenges - a survey. Informa Fus J 12(1):4-10

Endsley MR (1995) Toward a theory of situation awareness in dynamic systems. Hum Fact 37(1):32-64

Estrin D (2010) Participatory sensing: applications and architecture [internet predictions]. IEEE Int Comput 14(1):12-42

European Citizen Science Association (ECSA) (2015) ECSA ten principles of citizen science. http://ecsa.citizen-science.net/sites/ecsa.citizen-science.net/files/ ECSA_Ten_principles_of_citizen_science.pdf. Accessed Apr 2016

Feinmann J (2014) How MSF is mapping the world's medical emergency zones. BMJ 349:7540

Fishwick C (2014) Tomnod-the online search party looking for Malaysian Airlines flight MH370. Guardian, 14

Flynn JR (2007) What is intelligence? Beyond the Flynn effect. Cambridge University Press, Cambridge

Foody G (2015) Valuing map validation: the need for rigorous land cover map accuracy assessment in economic valuations of ecosystem services. Ecol Econ 11:23-28

Fore LS, Paulsen K, O'Laughlin K (2001) Assessing the performance of volunteers in monitoring streams. Freshwater Biol 46:109-123

Foster-Smith J, Evans SM (2003) The value of marine ecological data collected by volunteers. Biol Conserv 113:199-213

Geoghegan H, Dyke A, Pateman R, West S Everett G (2016) Understanding motivations for citizen science. Final report on behalf of UKEOF, University of Reading, Stockholm Environment Institute (University of York) and University of the West of England

Goldman J, Shilton K, Burke J, Estrin D, Hansen M, Ramanathan N, Reddy S, Samanta V, Srivastava M, West R (2009) Participatory sensing: a citizen-powered approach to illuminating the patterns that shape our world. Foresight \& Governance Project, White Paper, pp 1-15

Goodchild M (2007) Citizens as sensors: the world of volunteered geography. Geo J 69:211-221

Grey F (2009) The age of citizen cyberscience, CERN Courier, 29th April 2009. http:// cerncourier.com/cws/article/cern/38718. Accessed Jul 2011

Haklay M, Weber P (2008) Openstreetmap: user-generated street maps. IEEE Pervas Comput $7(4): 12-18$

Haklay M (2013) Citizen science and volunteered geographic information - overview and typology of participation. In: Sui DZ, Elwood S, Goodchild MF (eds) Crowdsourcing geographic knowledge. Springer, Berlin, pp 105-122

Haklay M (2015) Citizen science and policy: a European perspective. The Woodrow Wilson Center, Commons Lab, Washington, DC

Haklay M (2016) Volunteered geographic information, quality assurance. In: Richardson D, Castree N, Goodchild M, Liu W, Kobayashi A, Marston R (eds) The international encyclopedia of geography: people, the earth, environment, and technology. Wiley/AAG, Hoboken, NJ

Haklay M, Singleton A, Parker C (2008) Web mapping 2.0: the Neogeography of the Geoweb. Geography Compass 3:2011-2039. https://doi.org/10.1111/j.1749-8198.2008.00167.x

Higgins C, Williams J, Leibovici D, Simonis I, Davis M, Muldoon C, Genuchten P, O'Hare G (2016) Citizen OBservatory WEB (COBWEB): a generic infrastructure platform to facilitate the collection of citizen science data for environmental monitoring - work in progress. Int $\mathrm{J}$ Spat Data Infrastruct Res 11:20

International Telecommunications Union (ITU) 2013. Percentage of Individuals using the Internet 2000-2012, ITU (Geneva), June 2013. http://www.itu.int/en/ITU-D/Statistics/Documents/ statistics/2013/Individuals_Internet_2000-2012.xls. Accessed Mar 2016

Jepson P, Ladle RJ (2015) Nature apps: waiting for the revolution. Ambio 44(8):827-832 
Kaplan J (1956) The International Geophysical Year Program of the United States. In: Crary AP, Gould LM, Hulburt EO, Odishaw H, Smith WE (eds) Antarctica in the international geophysical year: based on a symposium on the Antarctic. American Geophysical Union, Washington, DC. https://doi.org/10.1029/GM001p0001

Kerson R (1989) Lab for the Environment. MIT Technol Rev 92(1):11-12

Kobori H, Dickinson JL, Washitani I, Sakurai R, Amano T, Komatsu N, Kitamura W, Takagawa S, Koyama K, Ogawara T, Miller-Rushing AJ (2016) Citizen science: a new approach to advance ecology, education, and conservation. Ecol Res 31(1):1-19

Koch W (2014) Tracking and sensor data fusion. Springer, New York, NY. https://doi.org/10.1007/978-3-642-39271-9

Krebs V (2010) Motivations of cybervolunteers in an applied distributed computing environment: MalariaControl.net as an example. First Monday, 15(2)-1 February 2010

Lease M, Alonso O (2014) Crowdsourcing and human computation, Introduction. Encyclopedia of social network analysis and mining (ESNAM), pp 304-315. http://link.springer.com/ referenceworkentry/10.1007/978-1-4614-6170-8_107. Accessed Apr 2016

Lin AYM, Huynh A, Lanckriet G, Barrington L (2014) Crowdsourcing the unknown: the satellite search for Genghis Khan. PLoS One 9(12):e114046

Lintott CJ, Schawinski K, Slosar A, Land K, Bamford S, Thomas D, Raddick MJ, Nichol RC, Szalay A, Andreescu D, Murray P, van den Berg J (2008) Galaxy zoo: morphologies derived from visual inspection of galaxies from the Sloan Digital Sky Survey. Month Not Roy Astronomic Soc 389(3):1179-1189

Mackechnie C, Maskell L, Norton L, Roy D (2011) The role of 'Big Society' in monitoring the state of the natural environment. J Environ Monit 13:2687

McCray WP (2006) Amateur scientists, the International Geophysical year, and the ambitions of Fred Whipple. Isis 97(4):634-658

McQuillan D (2014) The countercultural potential of citizen science. M/C J 17(6). http:// journal.media-culture.org.au/index.php/mcjournal/article/view/919. Accessed May 2016

Nascimento S, Guimarães Pereira A, Ghezzi A (2014) From citizen science to do it yourself science: an annotated account of an on-going movement. Joint Research Centre/European Commission, London

Newman C, Buesching CD, MacDonald DW (2003) Validating mammal monitoring methods and assessing the performance of volunteers in wildlife conservation - "Sed quis custodiet ipsos custodies?". Biol Conserv 113:189-197

Oxford English Dictionary (OED) (2014) Citizen science. Accessed Aug 2014

Parliamentary Office for Science and Technology (POST) (2014) POSTNote 476 Environmental Citizen Science, UK Parliament

Powney GD, Isaac NJ (2015) Beyond maps: a review of the applications of biological records. Biol J Linn Soc 115(3):532-542

Prestopnik N, Crowston A (2012) Purposeful gaming \& socio-computational systems: a citizen science design case. In Proceedings of GROUP'12, October 27-31, 2012, Sanibel Island, Florida, USA, pp 75-84.

Ravetz J (2006) The no-nonsense guide to science. New Internationalist

Reeves S (2013) Human-computer interaction issues in human computation. In: Michelucci P (ed) Human computation handbook. Springer, New York, pp 411-419

Salk CF, Sturn T, See L, Fritz S (2017) Limitations of majority agreement in crowdsourced image interpretation. Trans GIS 21:207. https://doi.org/10.1111/tgis.12194

Stevens M, Vitos M, Altenbuchner J, Conquest G, Lewis J, Haklay M (2014) Taking participatory citizen science to extremes. Pervas Comput IEEE 13(2):20-29

UNESCO Institute of Statistics (UIS) (2015) Enrolment by level of education, December 2015 release. UNESCO, Paris

Von Kaenel M, Sommer P, Wattenhofer R (2011) Ikarus: large-scale participatory sensing at high altitudes. In Proceedings of the 12th Workshop on Mobile Computing Systems and Applications. ACM, New York, NY, pp 63-68 
Willow Run Laboratories (1966) Peaceful uses of earth-observation spacecraft: Volume II: Survey of applications and benefits. Report 7219-1-F (II), Ann Arbor, Michigan, February 1966

World Meteorological Organisation (2001) Volunteers for weather, climate and water. Geneva, Switzerland, WMO No. 919

Zook M, Graham M, Shelton T, Gorman S (2010) Volunteered geographic information and crowdsourcing disaster relief: a case study of the Haitian earthquake. World Med Health Pol 2(2):7-33

Open Access This chapter is licensed under the terms of the Creative Commons Attribution 4.0 International License (http://creativecommons.org/licenses/by/4.0/), which permits use, sharing, adaptation, distribution and reproduction in any medium or format, as long as you give appropriate credit to the original author(s) and the source, provide a link to the Creative Commons license and indicate if changes were made.

The images or other third party material in this chapter are included in the chapter's Creative Commons license, unless indicated otherwise in a credit line to the material. If material is not included in the chapter's Creative Commons license and your intended use is not permitted by statutory regulation or exceeds the permitted use, you will need to obtain permission directly from the copyright holder. 